\title{
Surgical repair of descending thoracic and thoracoabdominal aortic aneurysm involving the distal arch: Open proximal anastomosis under deep hypothermia versus arch clamping technique
}

\author{
Jae Suk Yoo, MD, Joon Bum Kim, MD, PhD, Sung-Ho Jung, MD, PhD, Suk Jung Choo, MD, PhD, \\ Cheol Hyun Chung, MD, PhD, and Jae Won Lee, MD, PhD
}

\begin{abstract}
Background: Surgical repair of a descending thoracic and thoracoabdominal aortic aneurysm (DTA/TAAA) involving the distal arch is challenging and requires either deep hypothermic circulatory arrest (DHCA) or crossclamping of the distal arch. The aim of this study was to compare these 2 techniques in the treatment of DTA/ TAAA involving the distal arch.
\end{abstract}

\begin{abstract}
Methods: From 1994 to 2012, 298 patients underwent open repair of DTA/TAAA through a left thoracotomy. One hundred seventy-four patients with distal arch involvement who were suitable for either DHCA $(n=81)$ or arch clamping $(\mathrm{AC} ; \mathrm{n}=93)$, were analyzed. In-hospital outcomes were compared using propensity scores and inverse-probability-of-treatment weighting adjustment to reduce treatment selection bias.
\end{abstract}

\begin{abstract}
Results: Early mortality was $11.1 \%$ in the DHCA group and $8.6 \%$ in the $\mathrm{AC}$ group $(P=.58)$. Major adverse outcomes included stroke in 16 patients $(9.2 \%)$, low cardiac output syndrome in $15(8.6 \%)$, paraplegia in 10 $(5.7 \%)$, and multiorgan failure in $10(5.7 \%)$. After adjustment, patients who underwent DHCA were at similar risk of death (odds ratio $[\mathrm{OR}], 1.14 ; P=.80)$ and permanent neurologic injury $(\mathrm{OR}, 0.95 ; P=.92)$ to those who underwent AC. Although prolonged ventilator support ( $>24$ hours) was more frequent with DHCA than with AC (OR, 2.60; $P=.003$ ), DHCA showed a tendency to lower the risk of paraplegia (OR, $0.15 ; P=.057$ ).
\end{abstract}

Conclusions: Compared with AC, DHCA did not increase postoperative mortality and morbidity, except for prolonged ventilator support. However, DHCA may offer superior spinal cord protection to AC during repair of DTA/TAAA involving the distal arch. (J Thorac Cardiovasc Surg 2014;148:2101-7)

Open surgical repair of a descending thoracic aortic and thoracoabdominal aortic aneurysm (DTA/TAAA) involving the distal arch is challenging because simple proximal DTA crossclamping is not always possible and either deep hypothermic circulatory arrest (DHCA) or clamping of the aortic arch may be required to achieve proximal anastomosis. ${ }^{1,2}$ The advantages of DHCA are cited as excellent protections for the spine and visceral organs, a bloodless field, and no need for aortic crossclamping. ${ }^{3-5}$ Conversely, more time is required to decrease and increase the body temperature, as a result of which the risk of coagulopathy, systemic inflammatory response, cold pulmonary and myocardial damage, and left ventricular distention injury may be increased. ${ }^{6,7}$ Moreover, with the advancements in

\footnotetext{
From the Department of Thoracic and Cardiovascular Surgery, Asan Medical Center, University of Ulsan College of Medicine, Seoul, South Korea.

Disclosures: Authors have nothing to disclose with regard to commercial support. Presented at the 2013 American Heart Association Meeting, Dallas, Texas, November 16-20, 2013

Received for publication Jan 9, 2014; revisions received May 30, 2014; accepted for publication June 5, 2014; available ahead of print Aug 15, 2014.

Address for reprints: Joon Bum Kim, MD, PhD, Department of Thoracic and Cardiovascular Surgery, Asan Medical Center, University of Ulsan College of Medicine, 388-1 Pungnap-dong Songpa-gu, Seoul 138-736, South Korea (E-mail: jbkim1975@amc.seoul.kr).

$0022-5223 / \$ 36.00$

Copyright (c) 2014 by The American Association for Thoracic Surgery

http://dx.doi.org/10.1016/j.jtcvs.2014.06.068
}

various cardiopulmonary bypass (CPB) strategies and adjunct procedures for distal organ protection under mild or moderate hypothermia, profound hypothermia is no longer the only option for distal organ protection. ${ }^{8-10}$ However, when the aneurysm involves the distal arch, arch clamping (AC) is the only viable alternative to DHCA. The AC technique is also controversial, however, because gaining proximal control of the aorta between the great vessels is often challenging and requires extreme caution in handling the aortic arch, especially in the presence of a "shaggy aorta." 11,12 Furthermore, temporary occlusion of the left subclavian artery (LSCA) may potentially reduce spinal cord perfusion and increase the risk of spinal cord ischemic injury. ${ }^{11,13}$ There is currently no consensus on the optimal method for proximal control in open repair of DTA/TAAA involving the distal arch, and previous studies on this topic have been limited. Thus, the aim of this study was to compare the clinical outcomes of DHCA versus AC in the surgical repair of DTA/TAAA involving the distal arch.

\footnotetext{
METHODS

Patients

From January 1994 to December 2012, 298 patients underwent DTA/ TAAA repair through a left thoracotomy or a thoracoabdominal approach. Seventy-three patients whose aortic pathology did not involve the aortic
} 


$$
\begin{array}{ll}
\text { Abbreviations and Acronyms } \\
\text { AC } & =\text { arch clamping } \\
\text { CI } & =\text { confidence intervals } \\
\text { CPB } & =\text { cardiopulmonary bypass } \\
\text { CSF } & =\text { cerebrospinal fluid } \\
\text { CT } & =\text { computed tomography } \\
\text { DHCA } & =\text { deep hypothermic circulatory arrest } \\
\text { DTA/TAAA } & =\text { descending thoracic and } \\
& \text { thoracoabdominal aortic aneurysm } \\
\text { LSCA } & =\text { left subclavian artery } \\
\text { LV } & =\text { left ventricle } \\
\text { SVG } & =\text { saphenous vein graft }
\end{array}
$$

arch and allowed proximal DTA clamping were excluded. Distal arch involvement was defined as an aneurysm occurring at the isthmus level or one that involved the distal arch (Figure 1), so that simple crossclamping of the proximal DTA was impossible. Fifty-one patients with distal arch involvement for whom there was no alternative but to use DHCA were also excluded. Thus, 174 patients in whom either DHCA or AC was deemed possible were included in this study; 81 patients underwent DHCA and 93 patients underwent AC. The 174 procedures in this study were performed by 5 different surgeons. The use of the DHCA technique for each surgeon was as follows; A (46 of 86; 53.5\%), B (7 of 27; $25.9 \%$ ), C (4 of $26 ; 15.4 \%)$, D (17 of $23 ; 73.9 \%$ ), and E (7 of 12 ; $58.3 \%$ ). Some surgeons have favored open proximal anastomosis under DHCA, and others have tried to crossclamp the arch by any means possible. For extensive TAAA disease regardless of distal arch involvement, some surgeons preferred DHCA, based on the belief that profound hypothermia might offer superior protection to the spinal cord and distal organs. The choice of DHCA versus AC was primarily at the attending surgeon's discretion.

The present study protocol was approved by the ethics committee and institutional review board of our institution, and informed consent from individual patients was waived because of the retrospective nature of the study.

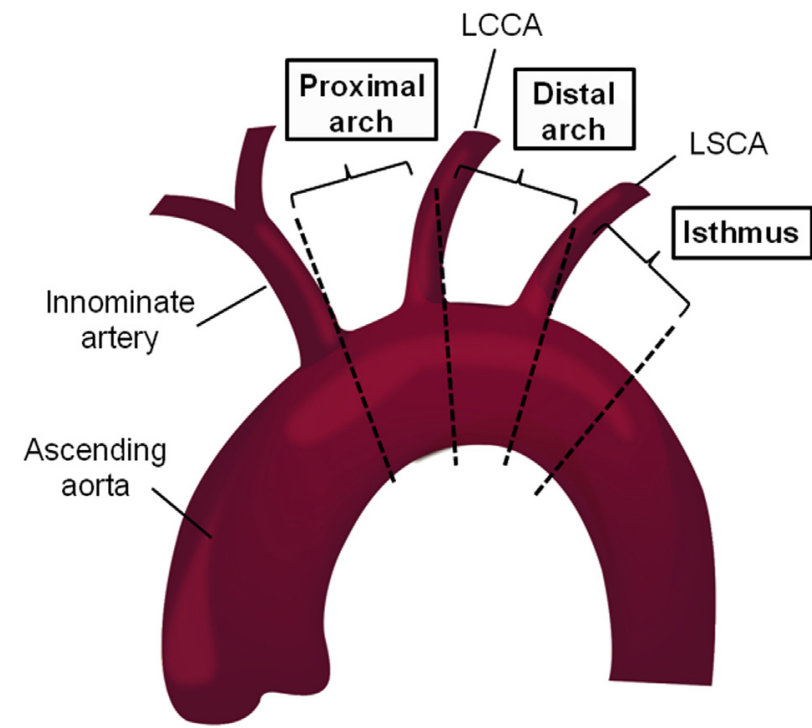

FIGURE 1. Aortic arch anatomy. LCCA, Left common carotid artery; $L S C A$, left subclavian artery.

\section{Operative Technique}

Patients were intubated with a double-lumen endotracheal tube. All procedures were performed through a left posterolateral thoracotomy or a thoracoabdominal approach via the fifth or sixth intercostal space. The DTA and abdominal aorta were dissected free to allow proximal and distal crossclamping and resection of the pathologic segments. The left femoral artery and vein were exposed through an oblique incision in the inguinal crease. After heparin sodium ( $3 \mathrm{mg} / \mathrm{kg}$ ) was administered, arterial and venous cannulation was established with a wire-directed approach. Transesophageal echocardiography was used to monitor the placement of the venous catheter in the right atrium. Vacuum-assisted venous drainage was used and additional cannulation was applied through the pulmonary artery when the flow was insufficient.

DHCA was used in 81 patients $(46.6 \%)$ and $\mathrm{AC}$ was used under partial femoro-femoral CPB in 93 patients $(53.4 \%)$ ). Of the 81 patients who underwent DHCA, the lowest nasopharyngeal temperature was 12 to $15^{\circ} \mathrm{C}$ in $28(34.6 \%), 15$ to $18^{\circ} \mathrm{C}$ in $33(40.7 \%)$, and 18 to $22^{\circ} \mathrm{C}$ in $20(24.7 \%)$. In the early period, surgeons preferred severe profound hypothermia based on the belief that it could provide superior protection to the spinal cord or other end organs. Recently, however, even surgeons who prefer DHCA for proximal control in our institution usually aim for a nasopharyngeal temperature not lower than 20 to $24^{\circ} \mathrm{C}$, because proximal anastomosis takes 15 to 20 minutes. A left atrial (LA) vent through the left superior or inferior pulmonary vein was used in $36(44.4 \%)$ patients in the DHCA group, and cardioplegia was not used. When the desired nasopharyngeal temperature was reached, circulatory arrest was initiated and the aorta was opened. Proximal aortic anastomosis was performed with a branched vascular graft in an open fashion without any selective antegrade cerebral perfusion techniques, after which extraarterial cannulation was added through the side branch of the graft so that dual perfusion to both the upper and lower body could be achieved. After placing a crossclamp distal to the side branch, partial CPB flow to the upper body was reinstituted. During the open proximal anastomosis under DHCA, the patient was placed in the Trendelenburg position, and while reinstituting upper body perfusion via the sidearm branch of the graft, the deairing procedure was performed at the same time, shortly before completing the proximal anastomosis.

In the $\mathrm{AC}$ group, the body temperature was lowered to 30 to $35^{\circ} \mathrm{C}$. Distal arch and separate LSCA clamping was conducted with beating-heart status. After proximal anastomosis, crossclamping was moved proximal to the graft. Distal anastomosis was performed in an open fashion when distal clamping was not feasible. When aortic replacement involved a visceral or renal segment, visceral/renal perfusion with cold blood was performed using separate balloon cannulas. After completion of the anastomoses, full CPB was resumed to both the upper and lower body. Cerebrospinal fluid (CSF) drainage was used routinely as an adjunct for spinal protection when the disease involved the aorta at the level between the T8 and L2 vertebrae $(n=105,60.3 \%)$.

\section{Statistical Methods}

Categorical variables are presented as frequencies and percentages, and continuous variables are expressed as the mean \pm standard deviation or the median with the range. Differences in baseline characteristics were compared using the unpaired $t$ test or Mann-Whitney $U$ test for continuous variables, and the $\chi^{2}$ test or the Fisher exact test for categorical variables, as appropriate. To reduce the impact of treatment selection bias and potential confounding in this observational study, we robustly accounted for significant differences in patient characteristics using weighted logistic regression analysis and inverse probability of treatment weighting. ${ }^{14}$ With this technique, weights for patients undergoing DTA/TAAA repair using DHCA were the inverse of the propensity scores, and weights for patients using the AC technique were the inverse of 1 - propensity scores. Stabilized weights were used to reduce the weights of treated patients with low propensity scores and untreated patients with high propensity scores. ${ }^{15}$ Propensity scores were estimated by multiple logistic regression analysis. 
All prespecified covariates were included in full nonparsimonious models for DHCA versus AC (Table 1). The model was well calibrated (Hosmer-Lemeshow test; $P=.46$ ) with reasonable discrimination $(\mathrm{C}$ statistic $=.70)$. Results are expressed as odds ratios $(\mathrm{OR})$ with $95 \%$ confidence intervals (CI). All reported $P$ values are 2 -sided. Statistical analyses were performed with SPSS version 18.0 (IBM Corp, Armonk, NY).

\section{RESULTS}

The unadjusted and adjusted baseline characteristics of the patients are shown in Table 1. There were no statistical differences in aortic diseases, rupture, shock, and emergency surgery between the 2 groups. The proportion of Crawford type I replacements was slightly higher in the AC group $(20.4 \%$ vs $9.9 \%, P=.055)$, but after adjustment, the patient distribution was well balanced $(P=.99)$. The rate of CSF drainage was also similar between the 2 groups. Concomitant coronary artery bypass grafting procedures were performed in 4 patients with the following anastomoses details: saphenous vein graft
(SVG) to the left anterior descending artery in 1, SVG to the obtuse marginal branch in 1 , and SVG to the posterior descending artery in 2 . The origins of the inflow were a descending thoracic aortic graft in 2 cases and native descending thoracic aorta in 2 cases.

The unadjusted early postoperative outcomes are summarized in Table 2 . The early death rate was $9.8 \%$ overall; $11.1 \%$ in the DHCA group and $8.6 \%$ in the AC group, with no significant intergroup statistical difference $(P=.58)$. The major complication rates were $38.3 \%$ and $31.2 \%$ in the DHCA and AC groups, respectively (no significant difference, $P=.33$ ). The incidence of low cardiac output syndrome showed a tendency to be higher in the DHCA group, but the difference was not significant $(12.3 \%$ vs $5.4 \%$, $P=.11)$. The stroke rate was similar in both groups; however, the paraplegia rate was significantly higher in the AC group $(9.7 \%$ vs $1.2 \%, P=.017)$, and prolonged mechanical ventilation was required more frequently in the DHCA group $(74.1 \%$ vs $49.5 \%, P=.001)$.

TABLE 1. Patient profiles at baseline

\begin{tabular}{|c|c|c|c|c|c|c|}
\hline \multirow[b]{2}{*}{ Characteristics } & \multicolumn{3}{|c|}{ Unadjusted data } & \multicolumn{3}{|c|}{ Data adjusted by IPTW } \\
\hline & $\begin{array}{c}\text { DHCA } \\
(\mathbf{N}=\mathbf{8 1}), \mathbf{n}(\%)\end{array}$ & $\begin{array}{c}\mathbf{A C} \\
(\mathbf{N}=\mathbf{9 3}), \mathbf{n}(\%)\end{array}$ & $P$ value & $\begin{array}{c}\text { DHCA } \\
(\mathbf{N}=\mathbf{8 1}), \mathbf{n}(\%)\end{array}$ & $\begin{array}{c}\text { AC } \\
(\mathbf{N}=\mathbf{9 3}), \mathbf{n}(\%)\end{array}$ & $P$ value \\
\hline Age $(y)$, mean \pm SD & $53.2 \pm 12.9$ & $54.1 \pm 14.2$ & .65 & $53.6 \pm 12.6$ & $53.5 \pm 14.3$ & .97 \\
\hline Female & $20(24.7)$ & $15(16.1)$ & .16 & 19.8 & 19.4 & .95 \\
\hline Diabetes mellitus & $3(3.7)$ & $8(8.6)$ & .19 & 4.9 & 6.5 & .75 \\
\hline Hypertension & $43(53.1)$ & $52(55.9)$ & .71 & 54.3 & 53.8 & .94 \\
\hline Disease of the aorta & & & .13 & & & .96 \\
\hline Aneurysm & $32(39.5)$ & $49(52.7)$ & .10 & 46.9 & 47.3 & .96 \\
\hline Chronic dissect & $42(51.9)$ & $34(36.6)$ & .05 & 44.4 & 43.0 & .85 \\
\hline Acute dissect & $7(8.6)$ & $10(10.8)$ & .80 & 8.6 & 9.7 & .81 \\
\hline Rupture & $6(7.4)$ & $7(7.5)$ & .98 & 6.2 & 6.5 & .94 \\
\hline Malperfusion & $2(2.5)$ & $1(1.1)$ & .48 & 1.2 & 1.1 & .92 \\
\hline Shock & $0(0)$ & $1(1.1)$ & .35 & 0 & 1.1 & .53 \\
\hline Hemothorax & $4(4.9)$ & $4(4.3)$ & .84 & 3.7 & 4.3 & .84 \\
\hline Urgent/emergency & $8(9.9)$ & $8(8.6)$ & .77 & 8.6 & 8.6 & .99 \\
\hline Extent of surgery & & & .15 & & & .84 \\
\hline Descending thoracic aorta only & $47(58.0)$ & $50(53.8)$ & .57 & 54.3 & 54.8 & .95 \\
\hline Descending thoracic segments & & & .17 & & & .95 \\
\hline Proximal third (A) & $17(21.0)$ & $25(26.9)$ & .38 & 18.5 & 18.3 & .97 \\
\hline Proximal two thirds (AB) & $14(17.3)$ & $10(10.8)$ & .27 & 16.0 & 14.0 & .83 \\
\hline Entire descending thoracic (ABC) & $16(19.8)$ & $15(16.1)$ & .56 & 21.0 & 22.6 & .80 \\
\hline \multicolumn{7}{|l|}{ Thoracoabdominal aorta } \\
\hline Crawford type I & $8(9.9)$ & $19(20.4)$ & .055 & 16.0 & 16.1 & .99 \\
\hline Crawford type II & $26(32.1)$ & $24(25.8)$ & .36 & 29.6 & 29.0 & .93 \\
\hline $\begin{array}{l}\text { Left ventricular ejection fraction (\%), } \\
\text { mean } \pm \mathrm{SD}\end{array}$ & $61.6 \pm 5.6$ & $61.0 \pm 5.4$ & .52 & $61.1 \pm 5.8$ & $61.2 \pm 5.3$ & .87 \\
\hline Preoperative aortic regurgitation & $26(32.1)$ & $20(21.5)$ & .11 & 24.7 & 24.7 & .99 \\
\hline $\operatorname{GFR}\left(\mathrm{mL} / \mathrm{min} / 1.73 \mathrm{~m}^{2}\right)$, mean $\pm \mathrm{SD}$ & $81.8 \pm 26.7$ & $81.5 \pm 34.3$ & .95 & $82.4 \pm 25.2$ & $82.1 \pm 33.5$ & .95 \\
\hline Cerebrospinal fluid drainage & $50(61.7)$ & $55(59.1)$ & .73 & 65.4 & 62.4 & .75 \\
\hline SIA reattachment & $6(7.4)$ & $17(18.3)$ & .043 & 13.6 & 14.0 & .94 \\
\hline Left atrial vent & $36(44.4)$ & - & & 45.7 & - & \\
\hline Concomitant CABG & $1(1.2)$ & $3(3.2)$ & .38 & 3.7 & 2.2 & .67 \\
\hline
\end{tabular}

$I P T W$, Inverse probability of treatment weighting; $D H C A$, deep hypothermic circulatory arrest; $A C$, arch clamping; $S D$, standard deviation; $G F R$, glomerular filtration rate; SIA, segmental intercostal artery; $C A B G$, coronary artery bypass grafting. 
TABLE 2. Early outcomes (unadjusted)

\begin{tabular}{|c|c|c|c|}
\hline Variables & DHCA $(\mathbf{N}=\mathbf{8 1}), \mathbf{n}(\%)$ & $\mathrm{AC}(\mathbf{N}=93), \mathbf{n}(\%)$ & $P$ value \\
\hline 30-d or in-hospital mortality & $9(11.1)$ & $8(8.6)$ & .58 \\
\hline Major complication & $31(38.3)$ & $29(31.2)$ & .33 \\
\hline Bleeding problem (reexploration + massive bleeding) & $11(13.6)$ & $14(15.1)$ & .78 \\
\hline Bleeding reexploration & $7(8.6)$ & $10(10.8)$ & .64 \\
\hline Requirement for new dialysis & $13(16.0)$ & $17(18.3)$ & .70 \\
\hline Low cardiac output syndrome* & $10(12.3)$ & $5(5.4)$ & .11 \\
\hline CVA/TIA & $8(9.9)$ & $8(8.6)$ & .77 \\
\hline Paraplegia & $1(1.2)$ & $9(9.7)$ & .017 \\
\hline Wound revision & $6(7.4)$ & $11(11.8)$ & .33 \\
\hline Pneumonia & $14(17.3)$ & $11(11.8)$ & .31 \\
\hline Visceral, leg ischemia & $4(4.9)$ & $1(1.1)$ & .13 \\
\hline Multiorgan failure & $4(4.9)$ & $6(6.5)$ & .67 \\
\hline Ventilation duration, $\mathrm{h}$ (interquartile range) & $52(12-86)$ & $24(23-94)$ & .51 \\
\hline Prolonged ventilation $(>24 \mathrm{~h})$ & $60(74.1)$ & $46(49.5)$ & .001 \\
\hline Prolonged ventilation $(>48 \mathrm{~h})$ & $41(59.4)$ & $28(40.6)$ & .006 \\
\hline Intensive care unit stay, $\mathrm{d}$ (interquartile range) & $7(3-9)$ & $5(5-10)$ & .55 \\
\hline Hospital stay, d (interquartile range) & $29(15-34)$ & $22(19-48)$ & .75 \\
\hline
\end{tabular}

DHCA, Deep hypothermic circulatory arrest; $A C$, arch clamping; $C V A$, cerebrovascular accident; $T I A$, transient ischemic attack. *Requiring mechanical support (intra-aortic balloon pulsation or venoarterial extracorporeal membrane oxygenation).

The adjusted ORs of adverse outcomes in the DHCA versus AC groups are summarized in Figure 2. After adjustment, there were no significant differences in the death rate and the major complication rate including death $(P=.80$ and $P=.56$, respectively). However, compared with the AC group, the DHCA group showed a tendency for a lower risk of paraplegia (OR, $0.15 ; 95 \% \mathrm{CI}, 0.02-1.06 ; P=.057)$ and a significantly increased risk of prolonged mechanical ventilation (OR, $2.60 ; 95 \% \mathrm{CI}, 1.39-4.87 ; P=.003)$.

\section{DISCUSSION}

In the open repair of DTA/TAAA, there have been advances in various adjunct procedures to protect spinal cord ischemia and visceral organ dysfunction, resulting in decreased rates of surgery-related morbidity and mortality. Contemporary data from several experienced large-volume aortic centers have shown superior outcomes (mortality rate around $7 \%-9 \%$ and paraplegia rate less than $6 \%)^{7,9}$ However, a recent meta-analysis on open surgical repair

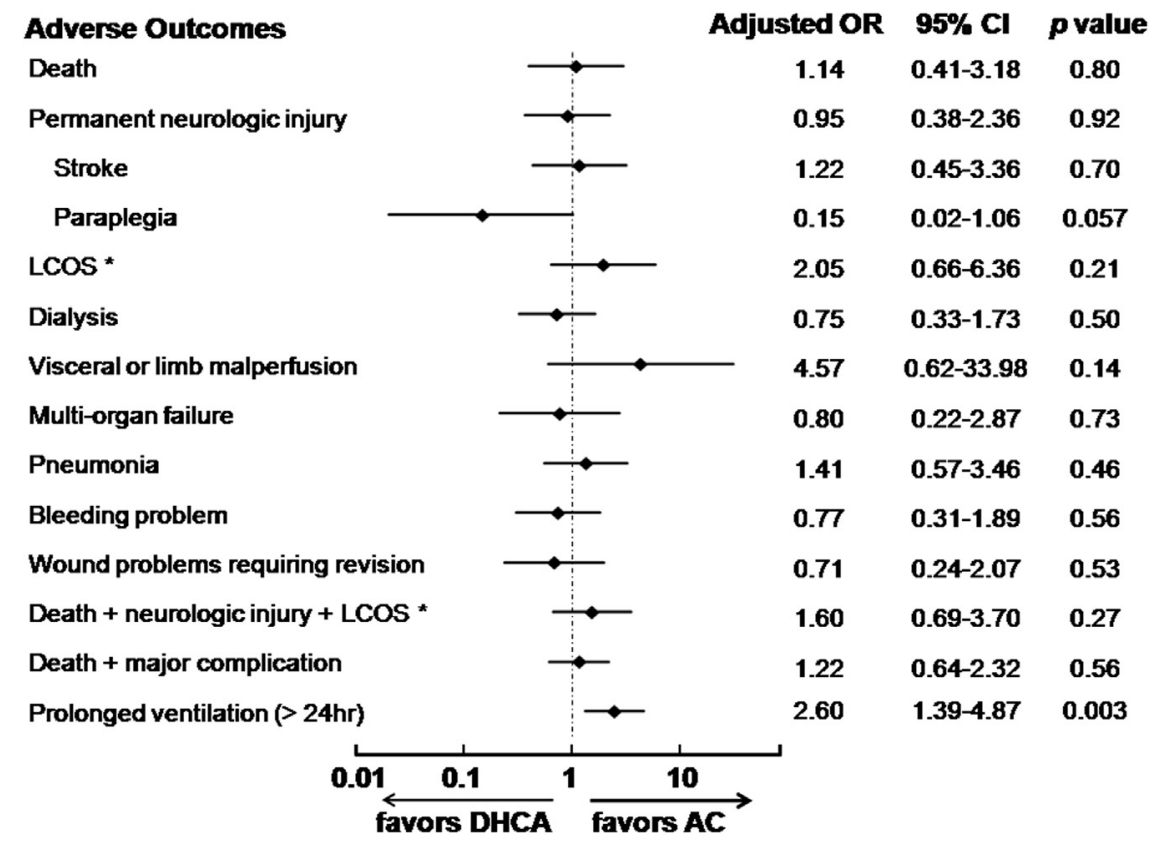

FIGURE 2. Forrest plot for adjusted odds ratios of adverse outcomes of deep hypothermic circulatory arrest compared with arch clamping. *Requiring mechanical support (intra-aortic balloon pulsation or venoarterial extracorporeal membrane oxygenation). OR, Odds ratio; $C I$, confidence interval; LCOS, low cardiac output syndrome; $D H C A$, deep hypothermic circulatory arrest; $A C$, arch clamping. 
of TAAA, which included 28 reports published between 2000 and 2010, demonstrated that despite a dramatic improvement in the surgical mortality and morbidity, the 30 -day mortality rate ranged from $4.2 \%$ to $18 \%$, the rate of spinal cord ischemia ranged from $2 \%$ to $28 \%$ (mean $7.5 \%$ ), and the rate of renal injury was also high, up to $40 \% .{ }^{16}$ These findings imply that open repair of DTA/ TAAA is still a challenging procedure for many cardiovascular surgeons.

Furthermore, DTA/TAAA involving the distal arch is even more challenging because extensive manipulation of the aortic arch for crossclamping is required, which may increase the risk of embolic stroke. Kay and colleagues ${ }^{1}$ reported on a simple clamp-and-sew technique without adjuncts for distal protection in 32 patients, resulting in a $6 \%$ mortality rate with no strokes despite $\mathrm{AC}$, but the rate of paraplegia was $9.4 \%$. Girardi and colleagues ${ }^{11}$ investigated the outcomes of AC during TAAA surgery and compared the results between patients with and without distal arch involvement. They concluded that AC did not increase the risk of mortality or major neurologic complications. By contrast, Okita and colleagues ${ }^{12}$ reported that $\mathrm{AC}$ was the strongest risk factor for stroke with arteriosclerotic aneurysms of the aortic arch. The only viable alternative to AC for proximal control in this type of DTA/TAAA surgery is DHCA. Several retrospective studies have shown acceptable early outcomes of DHCA in patients undergoing open DTA/TAAA repair. ${ }^{17,18}$ DHCA may provide superior protection to the spinal cord and visceral organs during prolonged procedures than any other form of partial bypass under moderate hypothermia. ${ }^{19,20}$ However, the routine use of DHCA for DTA/TAAA repairs is a debatable issue because of concerns about cerebral ischemia and myocardial protection, as well as hypothermic tissue damage, and systemic and pulmonary edema. ${ }^{21}$ In addition, the longer CPB time required to achieve DHCA, and the impairment of the coagulation cascade and platelet function induced by profound hypothermia may increase the risk of serious surgical bleeding. ${ }^{22}$

No previous studies to date have compared DHCA and AC for DTA/TAAA involving the distal arch. Therefore, this study is unique in comparing the outcomes of DHCA with the $\mathrm{AC}$ technique in this setting and has demonstrated similar overall clinical outcomes between the 2 patient groups. Although an increased risk of prolonged mechanical ventilation was associated with DHCA, it showed a decreased tendency for the risk of spinal cord injury.

\section{Higher Rate of Paraplegia in the AC Group}

The rate of paraplegia was higher in the AC group in this study (Table 2). Postoperative paraplegia occurred in only 1 patient in the DHCA group; it occurred in 9 patients in the AC group, 7 of whom (7 of 9; 77.8\%) underwent Crawford extent type I or II surgery. CSF drainage was used in these 7 patients (extent I or II; $100 \%$ ), and in 1 of the 2 patients with DTA only ( 1 of $2 ; 50 \%$ ). The results of our study support the collateral network concept described by Griepp and colleagues ${ }^{13}$; occlusion of the collateral flow from the LSCA or hypogastric artery may influence spinal cord ischemia, ${ }^{11}$ and mild or moderate hypothermia alone may not afford sufficient spinal cord protection during the clamping period. This hypothesis is also supported by data from the European Registry on Endovascular Aortic Repair Complications, ${ }^{23}$ which showed that extensive coverage of intercostal arteries alone was not associated with spinal cord injury, but simultaneous closure of the collateral vascular territories was highly related to the development of spinal cord injury. DHCA might be more advantageous in extensive procedures where the risk of spinal cord ischemia can be significant. The protective effect of homogeneous hypothermia on the spinal cord from aortic clamping-induced ischemia has been demonstrated in both experimental and clinical studies. ${ }^{3,19}$

\section{High Rate of Strokes in Both Groups}

The rate of strokes was high not only in the AC group but also in the DHCA group (Table 2). This may have been caused by factors other than the type of CPB strategy or clamping of the arch, such as retrograde perfusion from the femoral artery or the presence of increased embolic burden in the DTA or the arch itself. ${ }^{24}$ For example, if the embolic source is at the arch level, not only AC but the retrograde perfusion itself could be problematic. In the aortic condition where the embolic source is mainly located in the proximal DTA, open anastomosis under DHCA alone does not reduce the stroke risk much because the unprotected emboli can be dislodged into the arch vessels. For this clinical presentation, AC may be more protective against embolic stroke. In this regard, we reviewed the preoperative computed tomography (CT) images of the 16 patients who had postoperative stroke (Table 3). Twelve of these patients were found to have a preoperative embolic source in the aorta that was definitely visible on the CT images. Moreover, in 6 of the patients who underwent DHCA ( 6 of $7,85.7 \%$ ), embolic sources were located at the isthmus area.

\section{Prolonged Mechanical Ventilation in the DHCA Groups}

Another significant finding of the present study is that the need for prolonged mechanical ventilation was more frequent in the AC group (OR, 2.60; 95\% CI, 1.39-4.87; $P=.003$; Figure 2). Pulmonary complications are still the most common postoperative complications of DTA/TAAA repair, reported to be as high as $40 \% .{ }^{16}$ Obviously, the DHCA technique requires a longer operative time to increase and decrease the body temperature, as a result of 
TABLE 3. The relationship between the proximal control strategy and the presence or location of an embolic burden among the patients who had a postoperative stroke

\begin{tabular}{lccc}
\hline Patient & $\begin{array}{c}\text { Proximal } \\
\text { control }\end{array}$ & $\begin{array}{c}\text { Presence of an } \\
\text { embolic burden }\end{array}$ & $\begin{array}{c}\text { Location of the } \\
\text { embolic burden }\end{array}$ \\
\hline 1 & AC & + & Arch \\
2 & AC & + & Arch \\
3 & AC & + & Arch \\
4 & AC & + & Isthmus \\
5 & AC & + & Isthmus \\
6 & DHCA & + & Isthmus \\
7 & DHCA & + & Isthmus \\
8 & DHCA & + & Isthmus \\
9 & DHCA & + & Isthmus \\
10 & DHCA & + & Isthmus \\
11 & DHCA & + & Isthmus \\
12 & DHCA & + & Arch \\
13 & AC & - & - \\
14 & AC & - & - \\
15 & AC & - & - \\
16 & AC & - & -
\end{tabular}

which the risks of bleeding and pulmonary edema are also increased.

\section{High Rate of Major Complications in Both Groups}

The rate of major complications such as acute renal failure and low cardiac output was extraordinarily high in both groups even compared with the rates in the recent metaanalysis (Table 2). ${ }^{16}$ Although it is difficult to attribute the high rates of renal complications and low cardiac output to certain causes, we assume that those complications are closely related to the extensive nature of surgery involving the arch as well as perioperative bleeding complications related to such extensive surgery.

Furthermore, the heart under DHCA without cardioplegia might be more susceptible to myocardial damage. Myocardial distention injury may further critically compromise the outcomes for this particular type of surgery. However, an LA vent was used in only $44.4 \%$ of the patients who underwent DHCA in our study, and this we believe implies that the hypothermic technique was not applied in ideal fashion in many of the cases. In addition, a potentially suboptimal deairing procedure on the left ventricle (LV) without an $\mathrm{LV}$ vent could also have contributed to ischemic insult to the myocardium. Taking all these considerations into account, we have changed our strategy to assertively insert an LV vent (through the LV apex) when conducting DHCA.

In conclusion, in the surgical repair of DTA/TAAA involving the distal arch, either the DHCA or the AC technique may be feasible with similar results. Therefore, the CPB strategy should be based on the individual patient's condition (ie, aortic anatomy, embolic burden) and on the surgeon's preference.

\section{Limitations}

This study is subject to the limitations inherent in observational and retrospective data. The nonrandomized design may have affected the results because of unmeasured confounders, procedure bias, or detection bias, despite the use of rigorous statistical adjustment. This study represents the experience of a single, large, tertiary referral center, and might not be generalizable to other centers.

\section{References}

1. Kay GL, Cooley DA, Livesay JJ, Reardon MJ, Duncan JM. Surgical repair of aneurysms involving the distal aortic arch. J Thorac Cardiovasc Surg. 1986;91:397-404.

2. Kieffer E, Koskas F, Walden R, Godet G, Leblevec D, Bahnini A, et al. Hypothermic circulatory arrest for thoracic aneurysmectomy through left-sided thoractomy. J Vasc Surg. 1994;19:457-64.

3. Kouchoukos NT, Masetti P, Rokkas CK, Murphy SF, Blackstone EH. Safety and efficacy of hypothermic cardiopulmonary bypass and circulatory arrest for operations on the descending thoracic and thoracoabdominal aorta. Ann Thorac Surg. 2001;72:699-707.

4. Patel HJ, Shillingford MS, Mihalik S, Proctor MC, Deeb GM. Resection of the descending thoracic aorta: outcomes after use of hypothermic circulatory arrest. Ann Thorac Surg. 2006;82:90-6.

5. Soukiasian HJ, Raissi SS, Kleisli T, Lefor AT, Fontana GP, Czer LS, et al. Total circulatory arrest for the replacement of the descending and thoracoabdominal aorta. Arch Surg. 2005;140:394-8.

6. Safi HJ, Miller CC, Subramaniam MH, Campbell MP, Iliopoulos DC, O'Donnell JJ, et al. Thoracic and thoracoabdominal aortic aneurysm repair using cardiopulmonary bypass, profound hypothermia, and circulatory arrest via left side of the chest incision. J Vasc Surg. 1998;28:591-8.

7. Kulik A, Castner CF, Kouchoukos NT. Outcomes after thoracoabdominal aortic aneurysm repair with hypothermic circulatory arrest. J Thorac Cardiovasc Surg. 2011;141:953-60.

8. Crawford ES, Coselli JS, Safi HJ. Partial cardiopulmonary bypass, hypothermic circulatory arrest, and posterolateral exposure for thoracic aortic-aneurysm operation. J Thorac Cardiovasc Surg. 1987;94:824-7.

9. Coselli JS, Bozinovski J, LeMaire SA. Open surgical repair of 2286 thoracoabdominal aortic aneurysms. Ann Thorac Surg. 2007;83:S862-4.

10. Coselli JS, LeMaire SA, Koksoy C, Schmittling ZC, Curling PE. Cerebrospinal fluid drainage reduces paraplegia after thoracoabdominal aortic aneurysm repair: results of a randomized clinical trial. J Vasc Surg. 2002;35:631-9.

11. Girardi LN, Krieger KH, Mack CA, Lee LY, Tortolani AJ, Isom OW. Does crossclamping the arch increase the risk of descending thoracic and thoracoabdominal aneurysm repair? Ann Thorac Surg. 2005;79:133-8.

12. Okita Y, Ando M, Minatoya K, Kitamura S, Takamoto S, Nakajima N. Predictive factors for mortality and cerebral complications in arteriosclerotic aneurysm of the aortic arch. Ann Thorac Surg. 1999;67:72-8.

13. Etz CD, Kari FA, Mueller CS, Silovitz D, Brenner RM, Lin HM, et al. The collateral network concept: a reassessment of the anatomy of spinal cord perfusion. $J$ Thorac Cardiovasc Surg. 2011;141:1020-8.

14. Robins JM, Hernan MA, Brumback B. Marginal structural models and causal inference in epidemiology. Epidemiology. 2000;11:550-60.

15. Xu S, Ross C, Raebel MA, Shetterly S, Blanchette C, Smith D. Use of stabilized inverse propensity scores as weights to directly estimate relative risk and its confidence intervals. Value Health. 2010;13:273-7.

16. Piazza M, Ricotta JJ 2nd. Open surgical repair of thoracoabdominal aortic aneurysms. Ann Vasc Surg. 2012;26:600-5.

17. Weiss AJ, Lin HM, Bischoff MS, Scheumann J, Lazala R, Griepp RB, et al. A propensity score-matched comparison of deep versus mild hypothermia during thoracoabdominal aortic surgery. J Thorac Cardiovasc Surg. 2012;143:186-93.

18. Kouchoukos NT, Masetti P, Rokkas CK, Murphy SF. Hypothermic cardiopulmonary bypass and circulatory arrest for operations on the descending thoracic and thoracoabdominal aorta. Ann Thorac Surg. 2002;74:S1885-7.

19. Rokkas CK, Sundaresan S, Shuman TA, Palazzo RS, Nitta T, Despotis GJ, et al. Profound systemic hypothermia protects the spinal-cord in a primate model of spinal-cord ischemia. J Thorac Cardiovasc Surg. 1993;106:1024-35.

20. Etz CD, Zoli S, Kari FA, Mueller CS, Bodian CA, Di Luozzo G, et al. Redo lateral thoracotomy for reoperative descending and thoracoabdominal aortic repair: a consecutive series of 60 patients. Ann Thorac Surg. 2009;88:758-67. 
21. Kouchoukos NT, Masetti P, Murphy SF. Hypothermic cardiopulmonary bypass and circulatory arrest in the management of extensive thoracic and thoracoabdominal aortic aneurysms. Semin Thorac Cardiovasc Surg. 2003; 15:333-9.

22. Parr KG, Patel MA, Dekker R, Levin R, Glynn R, Avorn J, et al. Multivariate predictors of blood product use in cardiac surgery. J Cardiothorac Vasc Anesth. 2003; 17:176-81.
23. Czerny M, Eggebrecht H, Sodeck G, Verzini F, Cao P, Maritati G, et al. Mechanisms of symptomatic spinal cord ischemia after tevar: insights from the European Registry of Endovascular Aortic Repair Complications (EuREC). J Endovasc Ther. 2012;19:37-43.

24. Amarenco P, Cohen A. Atherosclerotic disease of the aortic-arch and the risk of ischemic stroke - a case-control study (preliminary results of the French Study of Aortic Plaques in Stroke). Stroke. 1994;25:259. 